\title{
ВЛИЯНИЕ ПАНДЕМИИ COVID-19 НА ДИАГНОСТИКУ РАКА В ПАТОЛОГОАНАТОМИЧЕСКОЙ СЛУЖБЕ НА ЮГЕ БРАЗИЛИЯ
}

\section{ОРИГИНАЛЬНАЯ СТАТЬЯ}

KLOCK, Julia Cristhina Monteiro', Borges, Giuliano Santos², OGATA, Daniel Cury ${ }^{3}$, KLOCK, Clóvis ${ }^{4}$

KLOCK, Julia Cristhina Monteiro. Et al. Влияние пандемии covid-19 на диагностику рака в патологоанатомической службе на юге Бразилия. Revista Científica Multidisciplinar Núcleo do Conhecimento. Год. 06, Изготовить. 11, Vol. 14, с. 182 -190. Ноябрь 2021 года. ISSN: 2448-0959, Ссылка доступа: https://www.nucleodoconhecimento.com.br/здравоохранение/патологоанатомичес кой-службе, DOI: 10.32749/nucleodoconhecimento.com.br/ru/103133

\section{СВОДКА}

Пандемия Covid-19 оказала значительное влияние на жизнь людей. Одно из этих воздействий может быть проверено при диагностике других заболеваний, особенно рака. Проблема: Как это повлияло на диагностику новых случаев рака в регионе, охваченном службой патологии на юге Бразилии во время пандемии? Общая цель: Оценить, произошло ли снижение числа диагнозов рака в патологоанатомической службе на юге Бразилии во время пандемии. Методология: Мы проанализировали отчеты о случаях, проведенные в лабораториях Infolaudo Group, в течение первых месяцев пандемии (апрель и май 2020 года) и сравнили с теми же месяцами 2019 года, чтобы измерить влияние пандемии на диагностику рака в службе патологии на юге Бразилия. Результаты: Сравнивая периоды апреля и мая 2019 года с аналогичным

\footnotetext{
${ }^{1}$ Студент-медик - Университет Моги дас Крузес. ORCID: 0000-0002-0834-193X.

${ }^{2}$ Специальность «Онкология», диплом по медицине. ORCID: 0000-0002-0737-7922.

${ }^{3}$ Доктор хирургических наук, магистр хирургии, специальность патология, диплом врача. ORCID 00000001-8819-2155.

${ }^{4}$ Аспирант по онкологии, специальность патология, диплом по медицине. ORCID 0000-0001-8456-0061.
}

RC: 103133

Доступно в:

https://www.nucleodoconhecimento.com.br/здравоохранение/патологоанатомичес кой-службе 
периодом 2020 года, было замечено снижение патологических процедур на $34,2 \%$. Некоторые виды рака, такие как толстая кишка, пищевод, грудь и простата, имели значительное снижение диагнозов, составить 19,7\%, 45\%, 18,2\% и 37,7\% соответственно. Вывод: С закрытием многих клиник и клиник на ранних стадиях пандемии наблюдалось снижение диагнозов рака в обследованных лабораториях.

Ключевые слова: пандемия, Covid-19, рак, патология.

\section{1. ВСТУПЛЕНИЕ}

По оценкам Всемирной организации здравоохранения (ВО3), к 2030 году во всем мире будет зарегистрировано 27 миллионов новых случаев рака, 17 миллионов смертей от этой болезни и 75 миллионов человек, живущих с раком (INCA, 2020).

Рак является основной причиной смерти в развитых и развивающихся странах (ALLGAR and NEAL, 2005). Тем не менее, некоторые виды рака имеют высокие шансы на излечение, если они обнаружены на ранней стадии и лечатся соответствующим образом (AMBUSAIDI and AL-BALUSHI, 2012).

Задержки в диагностике рака могут возникать на протяжении всего диагноза, в зависимости от уровней медицинской помощи: пациент, первичная медикосанитарная помощь и вторичная помощь.Диагнозы при более продвинутых опухолевых заболеваниях могут возникать, когда пациент медленно распознает и действует в отношении подозреваемых симптомов (ASCO, 2020). Эта низкая осведомленность о ранних симптомах рака считается преобладающей причиной позднего проявления, особенно когда симптомы имеют атипичный характер (ASCO, 2020). Другой возможный барьер может быть связан с высоким спросом на специализированные медицинские услуги и может в конечном итоге задержать диагностику, особенно в государственных службах (INCA, 2020).

RC: 103133 Доступно в: https://www.nucleodoconhecimento.com.br/здравоохранение/патологоанатомичес кой-службе 
В Бразилии, по данным THE INCA, в 2020 году было оценено 309230 новых случаев рака, у мужчин рак предстательной железы был ответственен за 29,2\% оценочных случаев. У женщин из 316140 новых случаев, как ожидается, рак молочной железы соответствовал 29,7\%. Эти данные не включают немеланомный рак кожи (GREEN et al., 2015).

В случае задержка в диагностике рака может происходить на нескольких уровнях.Пациент может не распознать подозреваемые симптомы рака или воздействовать на них.Врач первичной медико-санитарной помощи может не распознавать пациентов с подозрением на симптомы рака и исследовать их должным образом или вовремя направлять их.Пациенты с клиническим подозрением, находящийся во вторичной медицинской помощи, могут быть вовремя не замечены или могут быть направлены не на ту специальность.

Во время пандемии коронавируса принятые профилактические меры, такие как: социальное дистанцирование и карантин, повлияли на первоначальную диагностику онкологических больных. Таким образом, переполненность, наблюдавшаяся в нескольких больницах, делала невозможным правильную диагностику и лечение этих пациентов.

В этом сценарии данных из местной выборки не хватает, чтобы проверить, действительно ли пандемия повлияла на эту группу пациентов и диагнозы рака.

В связи с этим в настоящей статье в качестве ориентира имеется вопрос: каково было влияние на диагностику новых случаев рака в регионе, охваченном службой патологии на юге Бразилии во время пандемии? С общей целью оценки того, произошло ли снижение числа диагнозов рака в службе патологии на юге Бразилии во время пандемии

Были проанализированы данные с начала пандемии (апрель и май) 2020 года, в сравнении с данными за апрель и май 2019 года, из Службы патологии

RC: 103133 Доступно в: https://www.nucleodoconhecimento.com.br/здравоохранение/патологоанатомичес кой-службе 
Южного региона Бразилии (Infolaudo Group), чтобы признать текущую ситуацию и влияние периода lockdown на диагностику этой группы лиц.

Это поперечное и количественное эпидемиологическое исследование местной выборки.

\section{2. МАТЕРИАЛЫ И МЕТОДЫ}

Все отчеты о случаях за апрель и май 2020 года и апрель 2019 года были проанализированы, проведены в лабораториях Infolaudo Group, и они были сопоставлены друг с другом. Выбранные периоды были определены в связи с началом социальной изоляции и lockdown. Bce пациенты, включенные в это исследование, проходили лечение в регионе Фос реки Итажаи, долине Альто, Большом Флорианополисе и на севере и западе Риу-Гранди-ду-Сул (Erechim e Cruz Alta).

Все случаи с диагнозом рак были включены в исследование. Случаи, не имея подтверждения диагноза рака, были исключены. Собранные данные были включены в программу Microsoft Office Excel® 2010 году, и результаты были представлены в абсолютных цифррах и процентах. Это поперечное и количественное эпидемиологическое исследование местной выборки.

\section{3. ОБСУЖДЕНИЯ}

Задержки в первичной медико-санитарной помощи могут иметь место при распознавании, расследовании и направлении пациентов с подозрением на злокачественную неоплазию (ASCO, 2020).Хотя первичная медико-санитарная помощь является первым контактным пунктом для пациентов, пользующихся национальными службами здравоохранения в нескольких странах мира, задержка в диагностике рака остается постоянной проблемой на этом уровне (JONES et al., 2007). Ожидается, что врачи первичной медико-санитарной помощи будут выявлять пациентов с возможным заболеванием на ранней

RC: 103133

Доступно в:

https://www.nucleodoconhecimento.com.br/здравоохранение/патологоанатомичес кой-службе 
стадии. Тем не менее, диагноз рака относительно редко встречается для врача первичной медико-санитарной помощи, так как более 80\% пациентов имеют неспецифические симптомы (HARFORD, 2011).Фактически, основная задача этих медицинских работников состоит в том, чтобы дифференцировать меньшинство пациентов, которые нуждаются в срочной помощи, от тех, кто, вероятно, имеет самоограничные состояния (KAUFMAN et al., 2020).

В мае 2020 года Американское общество клинической онкологии (ASCO) опубликовало специальный доклад, рекомендующий отложить любые посещения клиники и любые скрининги рака или диагностику, а также процедуры, связанные со стадированием, если эта отсрочка не представляет риска прогрессирования заболевания или ухудшения прогноза (LONDON et al., 2020).

Некоторые международные исследования показывают, что снижение диагностики рака в первые месяцы пандемии составило 65,2\% новых случаев рака (LONDON et al., 2020).

Screening некоторых видов рака был нарушен, причем данные показывают, что рак молочной железы, толстой кишки и прямой кишки были наиболее затронуты с 89,2 и 84,5\% соответственно (MACLEOD et al., 2009).

В исследовании, проведенном в Соединенном Королевстве, lockdown вызвал приостановку скрининга рака, поставив под угрозу раннюю диагностику бесчисленных пациентов. Только из них пациенты с критической и симптоматической клинической картиной были направлены на диагностическое вмешательство. Записи о раке использовались в National Health Service (NHS) через базу данных больниц с пациентами в возрасте от 15 до 84 лет, у которых был диагностирован рак молочной железы (35583), колоректальный (24975) и рак пищевода (6744) в 2010 году с последующим наблюдением до 2014 года. У пациентов с первичной неоплазией легких (29305) 2012 год использовался в качестве года постановки диагноза, а 2015 год - в качестве окончательной RC: 103133 Доступно в: https://www.nucleodoconhecimento.com.br/здравоохранение/патологоанатомичес кой-службе 
даты наблюдения. С помощью блок-схемы для определения путей больных раком в NHS была сделана оценка для оценки последствий диагностической задержки у этой группы пациентов в течение 12 месяцев, начиная с марта 2020 года (дата lockdown), контекстуализация с ее воздействием через 1, 3 и 5 лет после первоначального диагноза. В данной методологии рассматривались три пути или потока этих пациентов, соответствующие от наилучшего к худшему сценарию. Исходя из этого, было оценено фактическое влияние выживаемости через 1, 3 и 5 лет после постановки диагноза, таким образом, рассчитано общее число смертей, связанных с раком, и общее количество потерянных лет жизни по сравнению с допандемическими данными.

Во всех сценариях увеличение смертности от рака молочной железы на 7,9\% до 9,6\% было оценено в течение 5 лет после постановки диагноза, что означает от 281 до 344 смертей, соответственно. При колоректальном раке увеличение составило от 15,3\% (1445) до 16,6\% (1563), а при раке легких это увеличение составило 4,8\% (1235) до 5,3\% (1372). Наконец, увеличение, наблюдаемое у пациентов с раком пищевода, составило от 5,8\% (330) до 6\% (342). Эти данные показывают, что в Великобритании наблюдается значительный рост предотвратимых смертей, вероятно, из-за ограничительных мер и мер социальной изоляции (MARINGE et al., 2020).

В другом исследовании, опубликованном Kaufman et al. (2020), наблюдалось снижение еженедельной заболеваемости раком на 40\% в Нидерландах и на 75\% в Соединенном Королевстве с начала пандемии covid-19. В этом исследовании использовалась методология, аналогичная нашей, оценивая записи базы данных с января по апрель 2019 года по сравнению с аналогичным периодом 2020 года. Они заметили значительные падения в диагностике злокачественных новообразований, in situ и неопределенного поведения. Во время пандемии еженедельное число случаев заболевания сократилось более чем на 46\% в шести наиболее распространенных типах рака, с вариациями на

RC: 103133

Доступно в:

https://www.nucleodoconhecimento.com.br/здравоохранение/патологоанатомичес кой-службе 
24,7\% в случаях неоплазии поджелудочной железы и на 51,8\% в случаях молочной железы (WHO, 2016).

Другая статья, опубликованная исследователями из Sidney Kimmel Center в Филадельфиии и NHS, показала снижение скрининга рака молочной железы на $89,2 \%$ и снижение колоноскопии на $85,5 \%$, что является важным инструментом для ранней диагностики колоректального рака (VOSE, 2020).

Bce кейсы Infolaudo Group в периоды марта и апреля 2020 года сравнивались с периодом марта и апреля 2019 года. Были выбраны месяцы март и апрель, поскольку они были первыми месяцами lockdown.

В 2019 году в апреле и мае в лаборатории Infolaudo Group поступило 5524 патологических процедуры, из которых 4634 были доброкачественными поражениями и 890 злокачественными поражениями, что составляет 16,1\%. В 2020 году за тот же период было проведено 3635 процедур, с 2875 доброкачественными поражениями и 760 злокачественными поражениями, представляющими злокачественные 20,9\%. Наблюдалось снижение патологических процедур на 34,2\%. (Диаграмма 1)

RC: 103133 Доступно в: https://www.nucleodoconhecimento.com.br/здравоохранение/патологоанатомичес кой-службе 
График 1: Снижение патологических процедур в апреле и мае 2020 года по отношению к аналогичному периоду 2019 года.

\section{Lesões benignas X Lesões malignas}

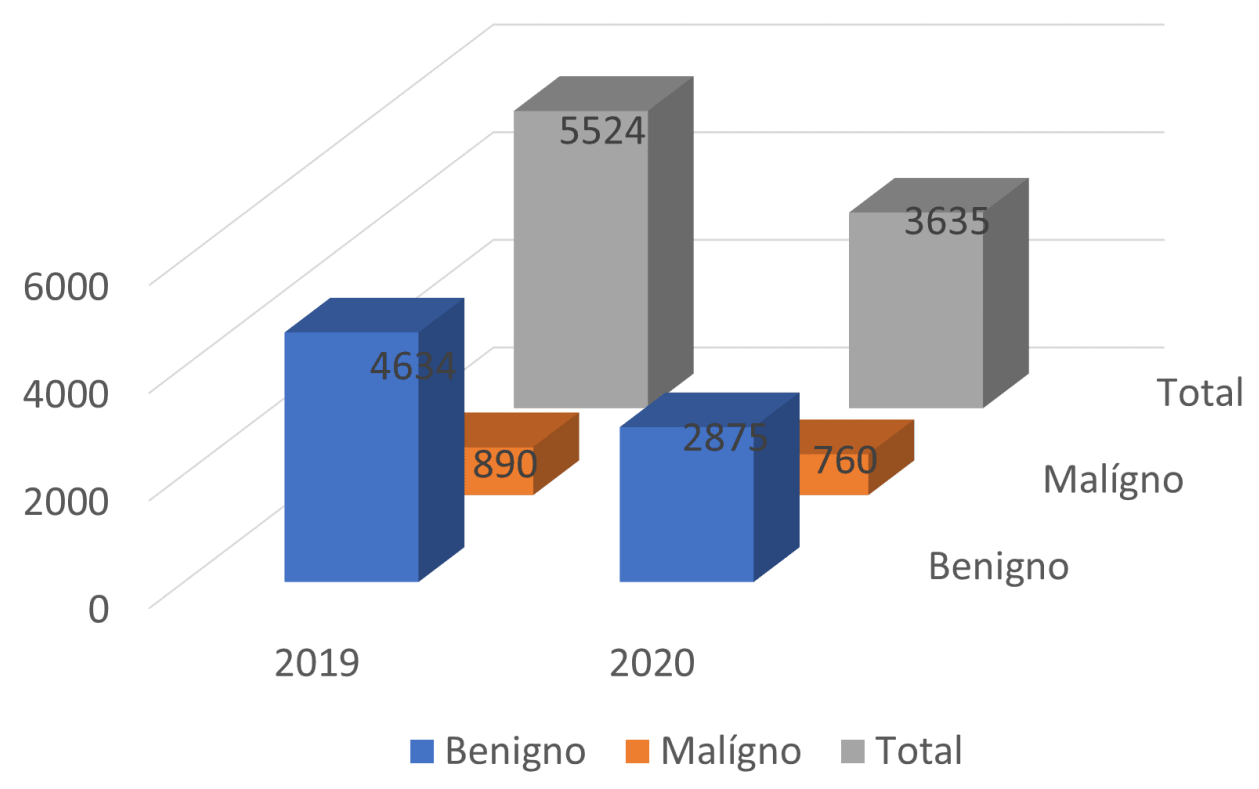

Источник: авторы

В целом, во всех различных процедурах наблюдалось снижение диагноза, будь то биопсия или хирургические образцы. Некоторые виды процедур имели более заметное снижение, например, крупные плановые операции, которые требовали госпитализации пациента.

Некоторые виды рака (график 2) имели более значительное снижение, такие как толстая кишка $(19,7 \%)$, пищевод $(45 \%)$, грудь $(18,2 \%)$ и простата $(37,7 \%)$.

RC: 103133

Доступно в:

https://www.nucleodoconhecimento.com.br/здравоохранение/патологоанатомичес кой-службе 
Графрик 2: снижение диагнозов рака (по органам), наиболее пострадавших в апреле и мае 2020 года по сравнению с аналогичным периодом 2019 года.

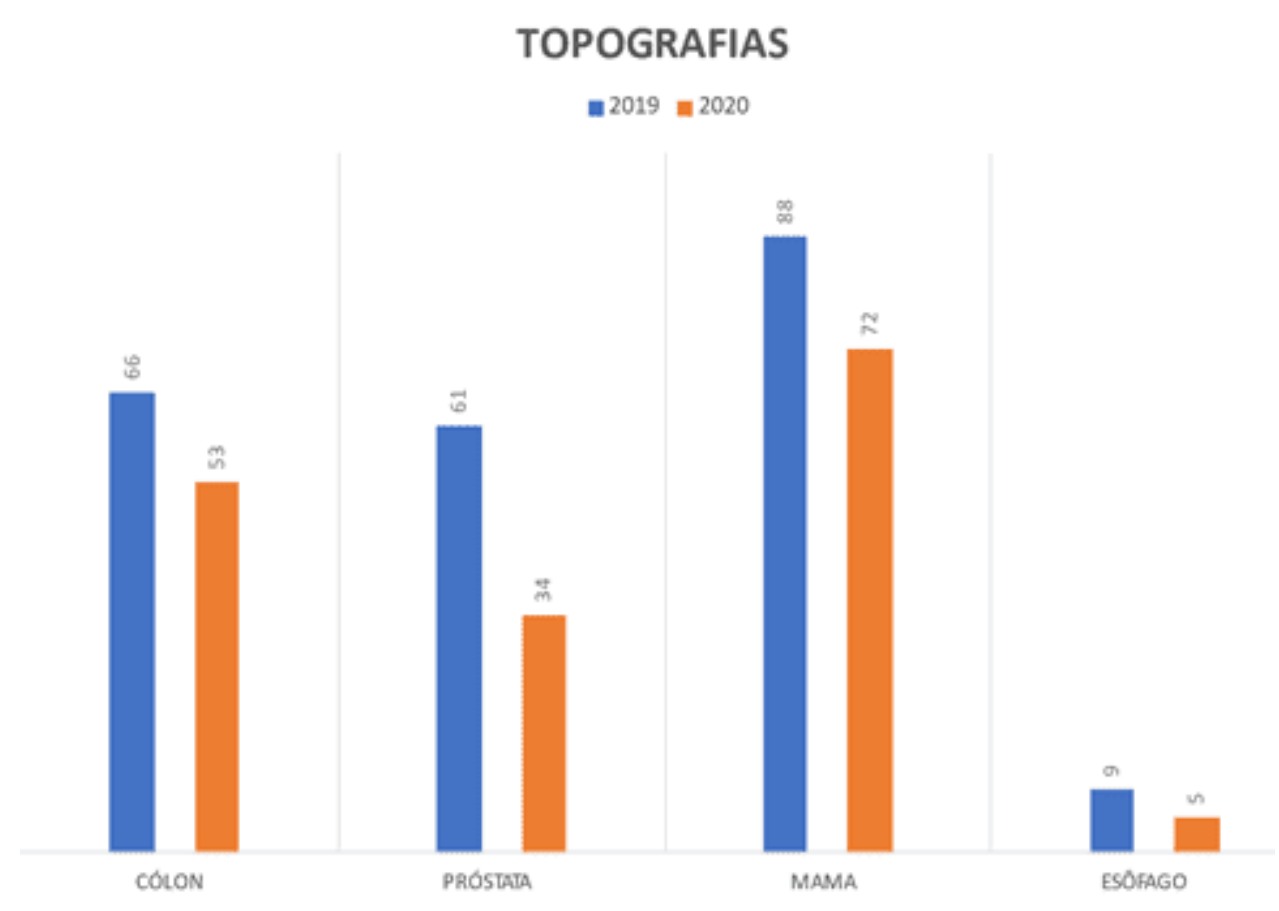

Источник: авторы.

Основное снижение было в случаях, которые потребовали бы какой-то инвазивной процедуры, и в случаях сакации пациента. Другие типы, такие как рак кожи, не уменьшаются за тот же период.

Хирургические блоки большинства больниц также ограничивали плановые операции из-за необходимости оставлять свободные койки, особенно койки в отделениях интенсивной терапии.

С последствиями закрытия многих клиник и клиник на ранних стадиях пандемии это оказало большое влияние на эти диагнозы. Помимо страха перед пациентами, покидающими свои дома, что также было одним из фракторов, которые помогли в этом снижении.

RC: 103133

Доступно в:

https://www.nucleodoconhecimento.com.br/здравоохранение/патологоанатомичес кой-службе 
Это исследование имеет некоторые ограничения. Во-первых, оценивалось только влияние блокады на диагностику в группе лабораторий, хотя это большая услуга. Таким образом, результаты настоящего исследования не обязательно применимы к другим центрам, поэтому для подтверждения этих результатов в национальном масштабе потребуются многоцентровые исследования. Возможно, что это вызвало смещение отбора. Однако этот метод отбора пациентов был идентичен для всех исследуемых периодов, что позволяло сравнивать.

\section{ОКОНЧАТЕЛЬНЫЕ СООБРАЖЕНИЯ}

Возвращаясь к правильному вопросу: как повлияло на диагностику новых случаев рака в регионе, охваченном службой патологии на юге Бразилии во время пандемии? Благодаря представленной исследованию удалось сделать вывод, что данные, проанализированные в отчетах пациентов, замеченных в Infolaudo Group, показали, что диагностика некоторых видов рака снизилась в начальный период пандемии в 2020 году с анализируемым периодом 2019 года, показав, что пандемия повлияла на этот тип диагностики. Также наблюдалось значительное снижение количества биопсий и хирургических образцов, полученных в этот период. Это объяснение может быть многофакторным и может зависеть от закрытия диагностических служб, таких как клиники и секторы больниц, а также от страха перед пациентами, обращающихся за медицинской помощью.

\section{ПЕРЕСМОТР БИБЛИОГРАФИЧЕСКИЙ}

ALLGAR, V. L.; NEAL, R. D. Delays in the diagnosis of six cancers: analysis of data from the National Survey of NHS Patients: Cancer. Br J Cancer, 2005.

AMBUSAIDI, A.; AL-BALUSHI, S. Educação em Saúde no Sultanato de Omã. In: Taylor, N. et al. (ed.). Educação em Saúde em Contexto. Editores Sense. 2012.

RC: 103133 Доступно в: https://www.nucleodoconhecimento.com.br/здравоохранение/патологоанатомичес кой-службе 
ASCO. American Society of Clinical Oncology. COVID-19 Patient Care Information. 2020. Disponível em: https://www.asco.org/asco-coronavirus-information/careindividuals-cancer-during-covid-19. Acesso em: 26 de jun. de 2020.

GREEN, T. et al. Cancer detection in primary care: insights from general practitioners. Ir. J Cancer, 2015.

HARFORD, J. B. Breast-cancer early detection in low-income and middleincome countries: do what you can versus one size fits all. Lancet Oncol, 2011.

INCA. Instituto Nacional de Câncer. Estimativa 2020: incidência de câncer no Brasil. Rio de Janeiro: INCA, 2020.

JONES, R. et al. Alarm symptoms in early diagnosis of cancer in primary care: cohort study using General Practice Research Database. BMJ, 2007.

KAUfMAN, H. W. et al. Changes in the Number of US Patients With Newly Identified Cancer Before and During the Coronavirus Disease 2019 (COVID-19) Pandemic. JAMA Netw Open, 2020.

LONDON, J. W. et al. Effects of the COVID-19 pandemic on cancer-related patient encounters. JCO Clinical Cancer Inform, 2020.

MACLEOD, $U$. et al. Risk factors for delayed presentation and referral of symptomatic cancer: evidence for common cancers. Br J Cancer, 2009.

MARINGE, C. et al. The impact of the COVID-19 pandemic on cancer deaths due to delays in diagnosis in England, UK: a national, population-based, modelling study. Lancet Oncol, 2020.

VOSE, J. M. Delay in Cancer Screening and Diagnosis During the COVID-19 Pandemic: What Is the Cost? Oncology (Williston Park), 2020.

RC: 103133 
WHO. World Health Organization. Facts about cancer. 2016. Disponível em: www.who.int

Добавлено: Ноябрь 2021.

Утверждено: Ноябрь 2021 года.

RC: 103133 Доступно в: https://www.nucleodoconhecimento.com.br/здравоохранение/патологоанатомичес кой-службе 